\title{
Quantitative analysis of paraspinal muscle atrophy after oblique lateral interbody fusion alone vs. combined with percutaneous pedicle screw fixation in patients with spondylolisthesis
}

Wei $\mathrm{He}^{1 \dagger}$, Da He $\mathrm{H}^{1 \dagger}$, Yuqing Sun', Yonggang Xing ${ }^{1}$, Mingming Liu', Jiankun Wen², Weiheng Wang ${ }^{2}$, Yanhai Xi ${ }^{2}$, Wei $\operatorname{Tian}^{1 *}$ and Xiaojian $Y \mathrm{e}^{2^{*}}$

\begin{abstract}
Background: There is no available literature for comparison on muscle atrophy between the "stand-alone" oblique lateral interbody fusion (OLIF) and regular OLIF (i.e., combined with percutaneous pedicle screws fixation (PPSF) in patients with spondylolisthesis). This study aimed to identify changes in back muscle atrophy between the two surgeries.

Methods: This was a retrospective cohort study of patients who underwent OLIF or OLIF+PPSF at Beijing Jishuitan Hospital and Shanghai ChangZheng Hospital between 07/2014 and 10/2017. Computed tomography (CT) was used to measure functional cross-sectional area (FCSA) and fat infiltration percentage (FIP) of the multifidus and erector spinae before and 24 months after surgery.

Result: There were no differences in FCSA and FIP between OLIF $(n=32)$ and OLIF+PPSF $(n=41)$ groups before surgery. In the OLIF group, the multifidus and erector spinae FCSA and FIP did not change at 24 months (FCSA: multifidus: from $8.59 \pm 1.76$ to $9.39 \pm 1.74 \mathrm{~cm}^{2}, P=0.072$; erector spinae: from $13.32 \pm 1.59$ to $13.55 \pm 1.31 \mathrm{~cm}^{2}, P=0.533$ ) (FIP: multifidus: from $15.91 \pm 5.30 \%$ to $14.38 \pm 3.21 \%, P=0.721$; erector spinae: from $11.63 \pm 3.05 \%$ to $11.22 \pm 3.12 \%, P=0.578)$. In the OLIF+PPSF group, the multifidus and erector spinae FCSA decreased (multifidus: from $7.72 \pm 2.69$ to $5.67 \pm 1.71 \mathrm{~cm}^{2}$, $P<0.001$; erector spinae: from $12.60 \pm 2.04$ to $10.15 \pm 1.82 \mathrm{~cm}^{2}, P<0.001$ ), while the FIP increased (multifidus: from $16.13 \pm 7.01 \%$ to $49.38 \pm 20.54 \%, P<0.001$; erector spinae: from $11.93 \pm 3.22 \%$ to $22.60 \pm 4.99 \%, P<0.001)$. The differences of FCSA and FIP between the two groups at 24 months were significant (all $P<0.001$ ). The patients in the standalone OLIF group had better VAS back pain, and JOA scores than the patients in the OLIF combined group (all $P<0.05$ ) at 1 week and 3 months after surgery. There were two cases (4.9\%) of adjacent segment degeneration in the OLIF combined group, while there was no case in the OLIF alone group.
\end{abstract}

Conclusions: Standalone OLIF had better clinical outcomes at 1 week and 3 months than OLIF+PPSF in patients with spondylolisthesis. OLIF may not result in paraspinal muscle atrophy at 24 months after surgery.

Keywords: Oblique lumbar interbody fusion, Percutaneous pedicle screw fixation, Paraspinal muscles atrophy, Functional cross-sectional area, Spondylolisthesis

\footnotetext{
* Correspondence: 2602248833@qq.com; xjyespine@smmu.edu.cn

${ }^{\dagger}$ Wei He and Da He contributed equally to this work.

'Department of Spine Surgery, Beijing Jishuitan Hospital, Beijing 100035,

China

${ }^{2}$ Department of Spine surgery, Shanghai ChangZheng Hospital, Shanghai

200003, China
}

(c) The Author(s). 2020 Open Access This article is distributed under the terms of the Creative Commons Attribution 4.0 International License (http://creativecommons.org/licenses/by/4.0/) which permits unrestricted use, distribution, and reproduction in any medium, provided you give appropriate credit to the original author(s) and the source, provide a link to the Creative Commons license, and indicate if changes were made. The Creative Commons Public Domain Dedication waiver (http://creativecommons.org/publicdomain/zero/1.0/) applies to the data made available in this article, unless otherwise stated. 


\section{Background}

Spondylolisthesis is the displacement (usually anterior) of a vertebral body relative to the adjacent inferior vertebral body [1, 2]. It typically affects children but is more symptomatic in adults [3]. Degenerative spondylolisthesis is the most common type in adults [1, 2]. High-grade spondylolisthesis is more common in women [4]. The reported prevalence is 2-6\% [2]. Spondylolisthesis is caused by the malfunction of the locking mechanism of the vertebral process between adjacent vertebrae [1]. The most common symptom is back pain; diagnosis can be confirmed by X-rays, magnetic resonance imaging (MRI), and computed tomography (CT) [2, 4]. Prognosis is generally good since $80-90 \%$ of the patients report good to excellent outcomes with conservative treatment, but surgery might be necessary for some patients $[2,4]$.

Interbody fusion is the cornerstone in the surgical treatment of an unstable degenerative lumbar spinal disease, and various techniques have been developed $[5,6]$. In recent years, posterior lumbar interbody fusion (PLIF) and transforaminal lumbar interbody fusion (TLIF) have become widely accepted treatments for patients with degenerative spondylolisthesis. Both techniques require extensive dissection of the paraspinal muscles as well as prolonged soft tissue retraction [7]. Complications include significant perioperative bleeding, dural tear, and postoperative muscular atrophy caused by denervation during surgery $[8,9]$.

The high incidence of paravertebral lumbar muscle injury after open techniques have raised the attention of surgeons for less morbid approaches. Oblique lateral interbody fusion (OLIF) was first introduced in 2012 [10]. Its primary surgical goal is to preserve the posterior column structure, thereby reducing paraspinal muscle trauma. Kim et al. [11] reported that a minimally invasive approach could reduce the markers of muscular injury and systemic inflammatory response. OLIF can be performed as a standalone procedure or in combination with screw fixation [12-14]. Nevertheless, to date, the benefits of standalone OLIF on the paraspinal muscles have not been defined. There is no available literature on the quantitative analysis of the possible difference in back muscle injury and atrophy between standalone OLIF and OLIF combined surgery in patients with spondylolisthesis.

Considering the emerging interest for these techniques, we conducted a retrospective study on the degree of paravertebral lumbar muscle atrophy of standalone OLIF vs. OLIF combined with percutaneous pedicle screws fixation (PPSF) in patients with degenerative spondylolisthesis of grade I operated at one of two hospitals. We sought to identify changes in back muscle atrophy between the two groups, with analysis of the impact of these changes on clinical outcomes.

\section{Material and methods Patient population}

This was a retrospective cohort study of patients who underwent standalone OLIF or OLIF combined with PPSF at the Beijing Jishuitan Hospital and Shanghai ChangZheng Hospital between July2014 and October 2017. The study was approved by the ethical committee of the Beijing Jishuitan Hospital (approval number: 201811-03) and the ethical committee of Shanghai Changzheng Hospital (approval number: 201812-01). Informed consent was waived because of the retrospective nature of the study.

The inclusion criteria were:1) underwent standalone OLIF or OLIF combined with PPSF at the L4-5 or L5S1level for grade I spondylolisthesis [15] with symptoms of radicular pain, intermittent neurogenic claudication, and mechanical low back pain; 2) failure to $>6$ months of conservative treatment;3) no previous history of lumbar surgical intervention at the L4-5or L5-S1 level; and 4) available24months of follow-up. The exclusion criteria were: 1) spinal canal stenosis; 2) caudaequina syndrome; 3) spinal tumor; 4) infection in the paraspinal area;5) vertebral fractures; or 6) previous surgery at the L4-5 or L5-S1 level.

\section{Surgical procedures}

All patients were operated by surgeons who had $>20$ years of experience in spinal surgery. In the standalone OLIF group, OLIF surgery was performed according to the standard procedure [16]. Briefly, under general anesthesia, the patients were placed in the lateral decubitus position on their right side, and the target intervertebral disc space was identified under fluoroscopic guidance. The presence of scoliosis does not affect the side of surgical approach. A 4-cmskin incision was made 6-10 cm anterior to the mid-portion of the marked disc. The surgical team approached the retroperitoneal space via blunt dissection and by mobilizing the peritoneum anteriorly to expose the anatomical oblique lateral corridor, followed by intervertebral cage insertion (Clydesdale spinal system, Medtronic, Memphis, TN, USA; $12 \times 50 \times$ $18 \mathrm{~mm}, 6^{\circ}$ lordotic, $3.27 \mathrm{cc}$ graft volume) filled with demineralized bone matrix (DBM) (Wright Medical Technology Inc., Arlington, TN, USA).

In the OLIF combined with the PPSF group, OLIF was performed based on the standard procedure [16]. After fusion, the patients were placed in the prone position to undergo posterior bilateral PPSF (CD Horizon Solera Voyager Spinal System; Medtronic, Memphis, TN, USA). 
None of the patients in both groups underwent additional laminectomy at the index level. Operative time and blood loss were recorded.

\section{Radiological assessment}

To assess the degree of paravertebral lumbar muscle atrophy of the patients of the two groups, we used the functional cross-sectional area (FCSA) protocol, as previously described $[17,18]$. Lumbar CT was performed using an Aquilion 64-slice scanner (Toshiba, Tokyo, Japan) before and 24 months after surgery. Using 5-mm thick slices, images were obtained with patients placed in the spine position. Images were stored in a digital imaging and communications in medicine (DICOM) format and analyzed on a personal computer using the Tissue Composition Module of the software (Mindways, Austin, TX, USA). The multifidus and erector spinae were measured in selected axial images at the lower third of the vertebral body(L3) above the operation level(L4/5) to avoid the artifact produced by the screws. Avoiding nearby fat, bony structures, and other soft tissues, the region of interest (ROI) was drawn with an electronic pencil. FCSA and fat infiltration percentage (FIP) of multifidus and erector spinae on the right side before surgery and 24 months after surgery were measured automatically by the software (Additional file 1: Figure S1). Adjacent segment degeneration was defined as narrowing intervertebral space and the disagreement of bilateral intervertebral space.

\section{Data collection}

History of osteoporosis (defined as T-score $<-2.5$ ) was verified from the medical charts. The clinical outcomes were based on the visual analog scale (VAS) score for pain and the Japanese Orthopaedic Association (JOA) score at 1 week, 3 months, and 2 years after operation. Erector spinae and multifidus were examined before surgery and 2 years after surgery. Degeneration of the adjacent segment was examined at 2 years after surgery.

\section{Statistical analysis}

Data analysis was performed using SPSS 18.0 (IBM, Armonk, NY, USA). Continuous variables are expressed as means \pm standard deviation and were analyzed using the Student's t-test. VAS and JOA scores were analyzed using repeated measure ANOVA with the post hoc paired samplet-test. Categorical variables are expressed as number (percentage) and were analyzed using Pearson's chi-square test or Fisher's exact test, as appropriate. A $P$ value $<0.05$ was considered statistically significant.

\section{Results}

Characteristics of the patients and operation data

Finally, 73 patients were included. The characteristics of the patients are presented in Table 1 . The standalone OLIF group included 10 men (31.2\%) and 22 women (68.8\%), with a mean age of $59.8 \pm 13.7$ years (range, 38 to 88 ). Among the 32 cages inserted, 30 (93.8\%) were located at the L4-5 level, and two (6.2\%) at L5-S1 level. The OLIF combined group included 11 men $(26.8 \%)$ and 30 women $(73.2 \%)$, with a mean age of $61.0 \pm 9.3$ years (range, 44 to 86 ). Among the 41 cages inserted, 37 (90.2\%) were located at the L4-5 level and four (9.8\%) at L5-S1 level. And no patient received arthrodesis in both groups. The operative time was significantly shorter in the standalone OLIF group than in the OLIF combined group (98 \pm 14 vs. $182 \pm 32 \mathrm{~min}, P<0.001$ ). There was significantly less blood loss in the standalone OLIF group than in the OLIF combined group $(108 \pm 49 \mathrm{ml}$ vs. $140 \pm 36 \mathrm{ml}, P=0.002$ ).

\section{Clinical outcomes}

The two groups showed significant improvement in all clinical outcome scores at all time points after surgery compared to preoperative data. The patients in the standalone OLIF group had better VAS back pain, and JOA scores than the patients in the OLIF combined group (all $P<0.05$ ) at 1 week and 3 months after surgery (Fig. 1 , Table 2). There were two cases (4.9\%) (Fig. 2) of adjacent segment degeneration in the OLIF combined group, while there was no case in the OLIF alone group. There was no significant difference in adjacent segment degeneration in the standalone OLIF group after surgery. In addition, no patient occurred implant migration in either group.

\section{Functional cross-sectional area of the multifidus and erector spinae}

The mean FCSA measurements are presented in Table 3. There were no differences between the two groups before

Table 1 Characteristics of the patients

\begin{tabular}{llll}
\hline & OLIF alone $(n=32)$ & OLIF+PPSF $(n=41)$ & P \\
\hline Gender & & & \\
$\quad$ Male & $10(31.3 \%)$ & $11(26.8 \%)$ & 0.679 \\
$\quad$ Female & $22(68.7 \%)$ & $30(73.2 \%)$ & \\
Age (years) & $59.8 \pm 13.7$ & $61.0 \pm 9.3$ & 0.669 \\
Level & & & \\
$\quad$ L4-5 & $30(93.8 \%)$ & $37(90.2 \%)$ & 0.584 \\
L5-S1 & $2(6.2 \%)$ & $4(9.8 \%)$ & \\
Osteoporosis & $8(25.0 \%)$ & $15(36.6 \%)$ & 0.290 \\
Operative time (min) & $98 \pm 14$ & $182 \pm 32$ & $<0.001$ \\
Blood loss (mL) & $108 \pm 49$ & $140 \pm 36$ & 0.002 \\
\hline OLIF Oliqu liter in
\end{tabular}

OLIF Oblique lateral interbody fusion, PPSF Percutaneous pedicle screw fixation 

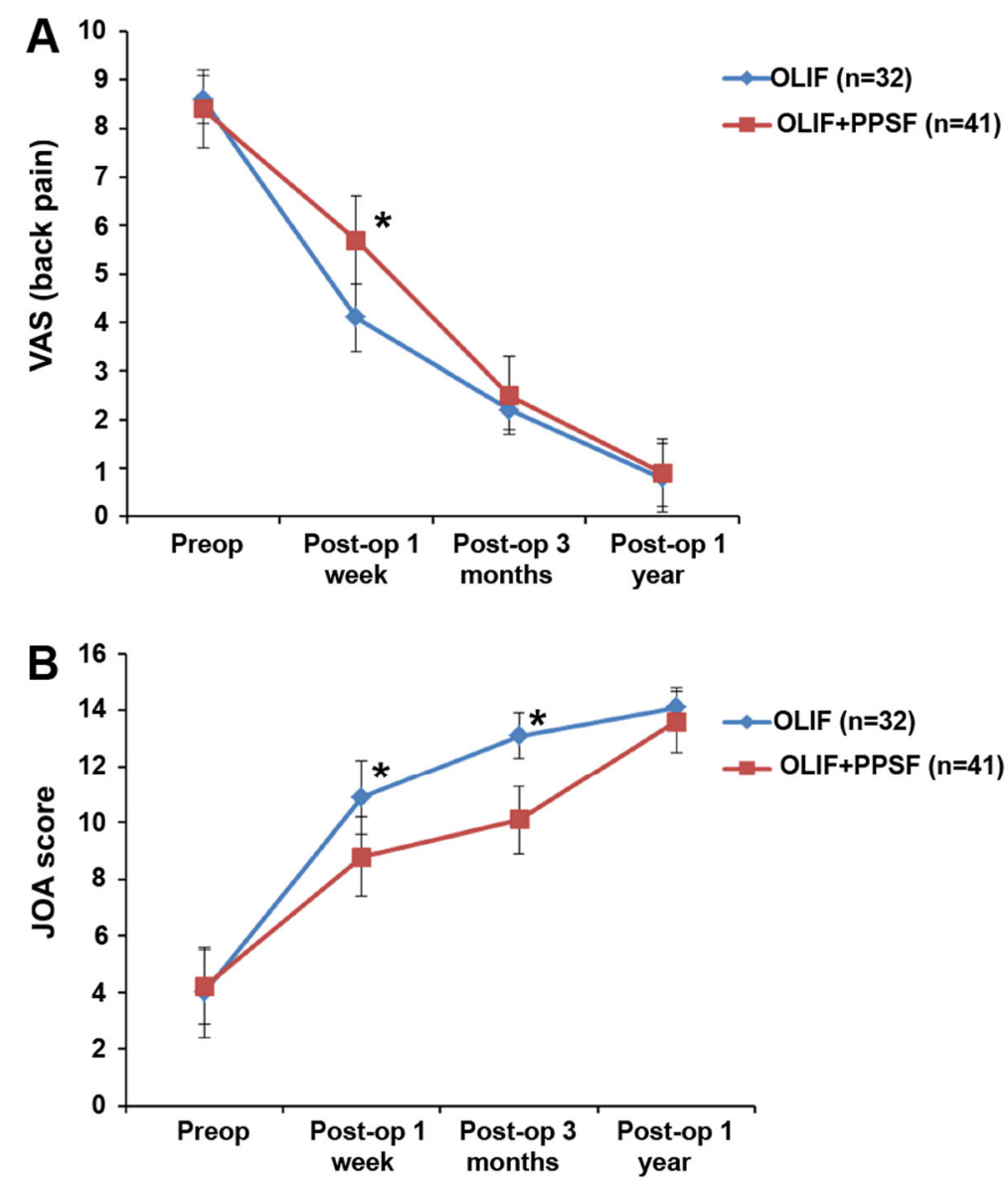

Fig. 1 Visual analog score (VAS) (a) of back pain and the Japanese Orthopaedic Association (JOA) score (b) before and after operation. OLIF: oblique lateral interbody fusion; PPSF: percutaneous pedicle screws fixation. *There were significant differences between the two groups at one week and three months after surgery

surgery. In the standalone OLIF group, the meanmultifidus and erector spinae FCSA did not change at 24 months (multifidus: from $8.59 \pm 1.76$ to $9.39 \pm 1.74 \mathrm{~cm}^{2}, P=0.072$; erector spinae: from $13.32 \pm 1.59$ to $13.55 \pm 1.31 \mathrm{~cm}^{2}, P=$ $0.533)$. In the OLIF combined group, the mean multifidus and erector spinae FCSA decreased after surgery (multifidus: from $7.72 \pm 2.69$ to $5.67 \pm 1.71 \mathrm{~cm}^{2}, P<0.001$; erector spinae: from $12.60 \pm 2.04$ to $10.15 \pm 1.82 \mathrm{~cm}^{2}, P<0.001$ ). The differences between the two groups at 24 months were significant (all $P<0.001$ ). Figure 3 shows an iatrogenic muscle injury.

\section{Fat infiltration percentage of the multifidus and erector spinae}

The mean FIP measurements are presented in Table 4 . There were no differences between the two groups before surgery. In the standalone OLIF group, the mean multifidus and erector spinae FIP did not change at 24 months (multifidus: from $15.91 \pm 5.30 \%$ to $14.38 \pm 3.21 \%, P=0.721$; erector spinae: from $11.63 \pm 3.05 \%$ to $11.22 \pm 3.12 \%, P=$ 0.578). In the OLIF combined group, the mean multifidus and erector spinae FIP increased after surgery (multifidus: from $16.13 \pm 7.01 \%$ to $49.38 \pm 20.54 \%, P<0.001$; erector spinae: from $11.93 \pm 3.22 \%$ to $22.60 \pm 4.99 \%, P<0.001$ ). There were significant differences between the two groups at 24 months (all $P<0.001$ ).

\section{Discussion}

Although conventional open TLIF or PLIF plus pedicle screw fixation are beneficial for the surgical treatment of spondylolisthesis, many factors might cause iatrogenic and degenerative changes to the back muscle after spinal fusion [19, 20]. OLIF addresses these issues because of the anterior approach [10], but PPSF can still be associated with muscle injury. Percutaneous pedicle screws are fixed to the vertebral pedicle throughout the subcutaneous fascia, paraspinal muscles, and articular processes. Moreover, the pedicle screw tail occupies a certain muscle volume. At the same time, the two screws (upper and lower vertebral bodies) need to be connected by a titanium rod, and the titanium rod is placed in the muscle layer. All the operations to place these devices cause 
Table 2 Surgical outcomes

\begin{tabular}{llll}
\hline & OLIF $(n=32)$ & OLIF+PPSF $(n=41)$ & $P$ \\
\hline VAS (back pain) & & & \\
Pre-op & $8.6 \pm 0.5$ & $8.4 \pm 0.8$ & 0.241 \\
Post-op 1 week & $4.1 \pm 0.7$ & $5.7 \pm 0.9$ & $<0.001$ \\
Post-op 3 months & $2.2 \pm 0.4$ & $2.5 \pm 0.8$ & 0.030 \\
Post-op 2 years & $0.8 \pm 0.7$ & $0.9 \pm 0.7$ & 0.831 \\
JOA score & & & \\
Pre-op & $4.0 \pm 1.6$ & $4.2 \pm 1.3$ & 0.636 \\
Post-op 1 week & $10.9 \pm 1.3$ & $8.8 \pm 1.4$ & $<0.001$ \\
Post-op 3 months & $13.1 \pm 0.8$ & $10.1 \pm 1.2$ & $<0.001$ \\
Post-op 2 years & $14.1 \pm 0.7$ & $13.6 \pm 1.1$ & 0.055 \\
$\begin{array}{l}\text { Adjacent segment } \\
\text { degeneration }\end{array}$ & 0 & $2(4.9 \%)$ & 0.125 \\
\hline
\end{tabular}

OLIF Oblique lateral interbody fusion, PPSF Percutaneous pedicle screw fixation, VAS Visual analog scale, JOA Japanese Orthopaedic Association

damage to the paravertebral muscles and cause muscle edema. Muscle damage can cause pain in the surgical site. There is no available literature on back muscle injury and atrophy between standalone OLIF and OLIF combined with PPSF in patients with spondylolisthesis. Therefore, this study aimed to identify changes in back muscle atrophy between the two groups. The results suggest that standalone OLIF may result in less important paraspinal muscle atrophy than OLIF combined with PPSF in patients with spondylolisthesis. This could contribute to better clinical outcomes at 24 months after surgery. Nevertheless, the faster recovery observed in the standalone OLIF group at least suggests that the patients can recover a normal life earlier than those with OLIF combined with PPSF.

One of the most important functions of the trunk muscles is to support the vertebral body. In particular, the extensor muscle of the lower lumber part plays a vital role in maintaining the balance of the lumbar levels and is also a dynamic stabilizer for the movement of the spine-pelvis complex. Atrophy of the back muscle correlates with clinical outcomes after vertebral fusion [21, 22]. Therefore, assessing muscle atrophy after spine surgery could help predict the outcomes. Hu et al. [23] demonstrated that FCSA assessed by CT is an acceptable method for evaluating paraspinal muscle atrophy, with a high consistency of 0.794 in the intraclass correlation between CT and MRI. Many studies have reported a decrease in the adjacent FCSA, ranging from -2 to $-38 \%$ using an open approach, compared with $+9.9 \%$ to $-12.2 \%$ using minimally invasive techniques [17, 24-26].

Kawaguchi et al. [27] reported that back muscle injury after posterior lumbar surgery is related to the operation time and retraction pressure. Therefore, he recommended that the retraction be released for $5 \mathrm{~min}$ after $1 \mathrm{~h}$ of retraction to prevent serious back muscle injury. Gejo et al. [28] also reported that the muscle retraction time influences the postoperative back muscle function. Datta et al. [29] and Taylor et al. [30] reported that $>2 \mathrm{~h}$ of retraction reduced the flow of capillary vessels, causing ischemic intramuscular changes.

Hyun et al. [31] reported that the paramedian interfascial approach might preserve the back muscle according to the midline and paramedian approaches in lumbar
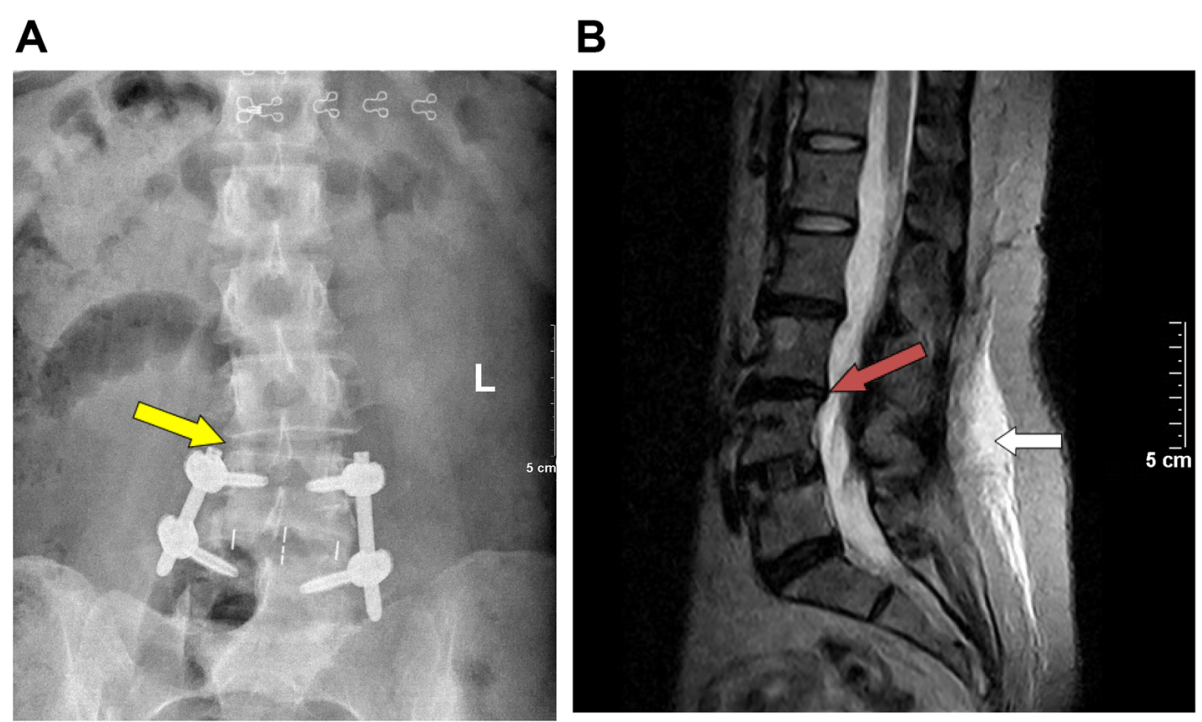

Fig. 2 a The disagreement regarding the bilateral intervertebral space. One side of the intervertebral height space at L3/4 is significantly smaller than on the other side (yellow arrow). $\mathbf{b}$ The red arrow indicates that the trailing edge of the L3 vertebral body above the L3/4 disc protrudes backward from the posterior edge of the $L 4$ vertebral body, suggesting that adjacent segment degeneration has occurred. The white arrow indicates postoperative edema of the fascia behind the lumbar spine in the regular OLIF group 
Table 3 Functional cross-sectional area of the multifidus and erector spinae before and 24 months after surgery

\begin{tabular}{|c|c|c|c|}
\hline & OLIF $(n=32)$ & OLIF+PPSF $(n=41)$ & $p^{a}$ \\
\hline \multicolumn{4}{|l|}{ Multifidus $\left(\mathrm{cm}^{2}\right)$} \\
\hline Pre-op & $8.59 \pm 1.76$ & $7.72 \pm 2.69$ & 0.099 \\
\hline Post-op 2 years & $9.39 \pm 1.74$ & $5.67 \pm 1.71$ & $<0.001$ \\
\hline $\mathrm{P}^{\mathrm{b}}$ & 0.072 & $<0.001$ & \\
\hline \multicolumn{4}{|l|}{ Erector spinae $\left(\mathrm{cm}^{2}\right)$} \\
\hline Pre-op & $13.32 \pm 1.59$ & $12.60 \pm 2.04$ & 0.104 \\
\hline Post-op 2 years & $13.55 \pm 1.31$ & $10.15 \pm 1.82$ & $<0.001$ \\
\hline$P^{b}$ & 0.533 & $<0.001$ & \\
\hline
\end{tabular}

OLIF Oblique lateral interbody fusion, PPSF Percutaneous pedicle screw fixation ${ }^{a}$ Comparison between the two groups

${ }^{\mathrm{b}}$ Comparison between pre- and post-operation

fusion, according to CT data. Therefore, OLIF has attracted considerable attention because OLIF uses the ante-psoas muscle approach, which theoretically avoids paraspinal muscle damage and decreases the risk of chronic low back pain. Nevertheless, CT is not appropriate to estimate the muscles at the fusion level on account of the interference by the metal artifacts [31, 32]. Therefore, methods to quantify muscle atrophy have been examined with the aim of analyzing the degree of paraspinal muscle atrophy [18]. In this study, standalone OLIF achieved better clinical outcomes (VAS and JOA scores) over the first 24 months after surgery compared with OLIF combined with PPSF.

These better clinical outcomes were probably associated with the better FCSA, and FIP found in the standalone OLIF group compared with the OLIF combined group. This observation is probably due to no invasion of the paraspinal muscles with standalone OLIF. Fan et al. [7] reported that there were significant differences not only in back pain VAS but also in the Oswestry disability index when they used the paramedian interfascial approach compared to the midline approach. Kim et al. [32] demonstrated that the atrophy of multifidus
Table 4 Fat infiltration percentage of the multifidus and erector spinae before and 24 months after surgery

\begin{tabular}{llll}
\hline & OLIF $(n=32)$ & OLIF+PPSF $(n=41)$ & $P^{a}$ \\
\hline Multifidus (\%) & & & \\
Pre-op & $15.91 \pm 5.30$ & $16.13 \pm 7.01$ & 0.885 \\
Post-op 2 years & $14.38 \pm 3.21$ & $49.38 \pm 20.54$ & $<0.001$ \\
P b & 0.721 & $<0.001$ & \\
Erector spinae (\%) & & & 0.686 \\
$\quad$ Pre-op & $11.63 \pm 3.05$ & $11.93 \pm 3.22$ & $<0.001$ \\
Post-op 2 years & $11.22 \pm 3.12$ & $22.60 \pm 4.99$ & \\
\hline P & 0.578 & $<0.001$ & \\
\hline
\end{tabular}

OLIF Oblique lateral interbody fusion, PPSF Percutaneous pedicle screw fixation ${ }^{a}$ Comparison between two groups

${ }^{\mathrm{b}}$ Comparison between pre- and post-operation

muscles appeared less important and trunk extension muscle strength was better preserved in patients who underwent PPSF compared to patients who received open surgery. Paraspinal muscles surrounding the surgical site are damaged due to iatrogenic denervation, as observed for the MF [33] and longissimus [34, 35] muscles, which are innervated by the medial branch nerve and in part by the intermediate branch nerve of the posterior rami. In a cadaver study, a medial branch nerve affection rate of $84 \%$ was described when inserting a screw via the mini-open surgical approach [36]. Accordingly, $\mathrm{Hu}$ et al. [37] also reported atrophy of the back muscle due to denervation of the paraspinal muscle, based on the results of a small animal study. Because the medial and intermediate branch nerves have the same origin, which is lateral to the facet joints and superior to the transverse processes [34], the insertion of pedicle screws may damage both nerves.

There were two cases of adjacent segment degeneration in the OLIF combined group, but none in the standalone OLIF alone. We believe that strong fixation results in a long-term disuse paraspinal muscle atrophy and further accelerate the degeneration of adjacent

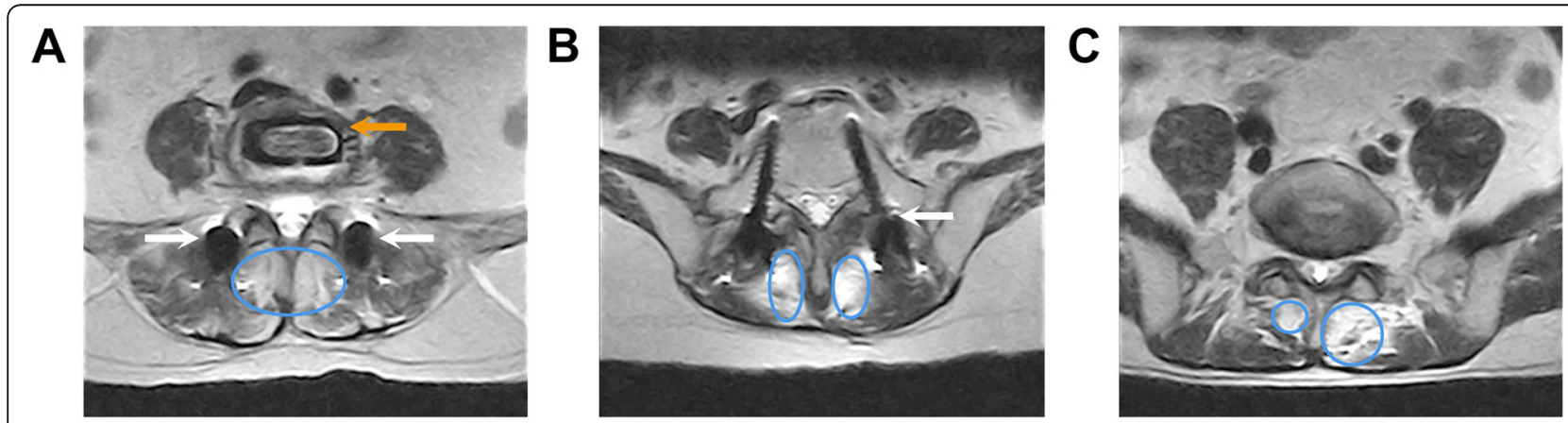

Fig. 3 latrogenic paravertebral muscle injury at fusion cage level (a); pedicle screw level (b) and adjacent segment level (c). A large number of non-muscle tissues (high signal area in the blue circle) occupying the original muscle position 2 years after surgery. The white arrow indicates the pedicle screw. The orange arrow indicates the intervertebral cage 
segments. First, the process of placing the pedicle screw and the titanium rod affects the small facet joints of the adjacent segments. Second, paravertebral muscles are damaged, and muscle strength is reduced, which may accelerate the instability of adjacent segments. Strube et al. [26] reported that the overall atrophy and fatty degeneration ratio at the adjacent segments after the anterioronly treatment option (ALIF) appears to be rather low. Regarding motion-preserving surgical treatment such as total disc replacement, a significantly lower ratio of adjacent-segment degeneration was reported compared with the fusion approach [38]. Interestingly, a higher rate of adjacent-segment degeneration was also observed for a transpedicular stabilized fixation where a posterior surgical approach was used [39]. Nevertheless, unilateral fixation has a lower incidence of degeneration than bilateral fixation in the proximal stage. BPS fixation was found to be overrigid, which would cause device-related osteoporosis, absorption of grafted bone, and degeneration of adjacent segments [39-41]. According to previous studies and the results of the present study, regarding the development or progression of adjacentsegment degeneration, we think that it may be predominantly related to muscle atrophy as well as over-rigid fixation.

The present study suggests that even though OLIF combined with PPSF can be done using a mini-open or percutaneous technique, there is still a risk of paraspinal muscle denervation. These findings agree with previous studies. Regev et al. [36] reported that percutaneous screw application could potentially reduce the indirect damage caused to the medial branch nerve from $84 \%$ to $20 \%$. Alternative surgical approaches such as stand-alone ALIF [42] or different screw entry points such as cortical screw-rod fixation [43] would completely avoid affection of the medial and intermediate branch nerves. Other studies showed that iatrogenic alterations decrease postoperative cross-sectional area (CSA) and contractile tissue density of back muscles [20,44, 45].

In this study, FIP of multifidus and erector spinae at 2 years after surgery was higher than before surgery in the OLIF combined group. The reason could be that the multi-cleft muscle is adjacent to the vertebral spinous process. Due to the compression of the percutaneous pedicle screw channel to the midline during the operation, the multifidus is sandwiched between the spinous process and the channel, so the internal part of the fissure muscle is more prone to edema. On the other hand, there was no difference in FIP of the two muscles in the standalone OLIF group after surgery. This result is consistent with the FCSA results. Therefore, we believe that an increase in the fat percentage in the paravertebral muscle is another important factor in accelerating muscle atrophy after fusion.
This study has limitations. The number of patients was small. This was a retrospective study with all the inevitable biases. There was no randomization, and a variety of factors could have affected the selection of the surgical approach. Finally, factors such as general condition, comorbidities, and neurological conditions were not considered. Further studies are required to confirm whether muscle injury is directly related to the longterm clinical outcome.

\section{Conclusion}

In conclusion, standalone OLIF can achieve better clinical outcomes compared with OLIF combined with PPSF for grade I spondylolisthesis, as shown by less back pain at 1 week and 3 months after operation. OLIF may not result in paraspinal muscle atrophy at 24 months after surgery.

\section{Supplementary information}

Supplementary information accompanies this paper at https://doi.org/10. 1186/s12891-020-3051-9.

Additional file 1: Figure S1. Measurement of the functional crosssectional area and fat infiltration percentage. Green circles show the multifidus (A) and erector spinae (B). The functional cross-sectional areas and fat infiltration percentageswere measured automatically by the software.

\section{Abbreviation \\ CT: Computed tomography; FCSA: Functional cross-sectional area; FIP: Fat infiltration percentage; MRI: Magnetic resonance imaging; OLIF: Oblique lateral interbody fusion; PLIF: Posterior lumbar interbody fusion; PPSF: Percutaneous pedicle screws fixation; TLIF: Transforaminal lumbar interbody fusion}

\section{Acknowledgments \\ None.}

\section{Authors' contributions}

WH and DH carried out the studies and drafted the manuscript. YQS and YGX performed the statistical analysis and participated in its design. MML, JKW, WHW and YHX collect data. WT and XJY participated in acquisition, analysis, or interpretation of data and draft the manuscript. All authors read and approved the final manuscript.

\section{Funding}

This study was funded by Beijing Jishuitan Hospital "Nova Program" (\#XKXX201808), Beijing Hospital Authority Youth Program (\#QML20190403), Beijing Jishuitan Hospital "Medical and Engineering Intersection Project" (\#YGQ-201924), and Beijing "Ten, Hundred, Thousand" Medical Talents Project: "Application of computer navigation-assisted minimally invasive surgery and traditional surgery in lumbar degenerative disease".

\section{Availability of data and materials}

The datasets used and/or analyzed during the current study are available from the corresponding author on reasonable request.

Ethics approval and consent to participate

The study was approved by the ethical committee of the Beijing Jishuitan Hospital (approval number: 201811-03) and the ethical committee of Shanghai Changzheng Hospital (approval number: 201812-01). Informed consent was waived because of the retrospective nature of the study. 


\section{Competing interests}

The authors declare that they have no competing interests.

Received: 13 November 2019 Accepted: 7 January 2020 Published online: 14 January 2020

\section{References}

1. Burke CJ, Shah D, Saha S, Houghton R. Spondylolisthesis: a pictorial review. Br J Hosp Med (Lond). 2012;73(12):691-5.

2. Alfieri A, Gazzeri R, Prell J, Rollinghoff M. The current management of lumbar spondylolisthesis. J Neurosurg Sci. 2013:57(2):103-13.

3. Agabegi SS, Fischgrund JS. Contemporary management of isthmic spondylolisthesis: pediatric and adult. Spine J. 2010;10(6):530-43.

4. Tallarico RA, Madom IA, Palumbo MA. Spondylolysis and spondylolisthesis in the athlete. Sports Med Arthrosc Rev. 2008;16(1):32-8.

5. Rhee JM, Schaufele M, Abdu WA. Radiculopathy and the herniated lumbar disc. Controversies regarding pathophysiology and management. J Bone Joint Surg Am. 2006;88(9):2070-80.

6. Gregory DS, Seto CK, Wortley GC, Shugart CM. Acute lumbar disk pain: navigating evaluation and treatment choices. Am Fam Physician. 2008;78(7) 835-42

7. Fan SW, Hu ZJ, Fang XQ, Zhao FD, Huang Y, Yu HJ. Comparison of paraspinal muscle injury in one-level lumbar posterior inter-body fusion: modified minimally invasive and traditional open approaches. Orthop Surg. 2010;2(3):194-200

8. Phan K, Maharaj M, Assem Y, Mobbs RJ. Review of early clinical results and complications associated with oblique lumbar interbody fusion (OLIF). J Clin Neurosci. 2016:31:23-9.

9. Wang YP, An JL, Sun YP, Ding WY, Shen Y, Zhang W. Comparison of outcomes between minimally invasive transforaminal lumbar interbody fusion and traditional posterior lumbar intervertebral fusion in obese patients with lumbar disk prolapse. Ther Clin Risk Manag. 2017;13:87-94.

10. Silvestre C, Mac-Thiong JM, Hilmi R, Roussouly P. Complications and morbidities of mini-open anterior retroperitoneal lumbar Interbody fusion: oblique lumbar Interbody fusion in 179 patients. Asian Spine J. 2012;6(2):89-97.

11. Kim KT, Lee SH, Suk KS, Bae SC. The quantitative analysis of tissue injury markers after mini-open lumbar fusion. Spine (Phila Pa 1976). 2006;31(6): 712-6.

12. Zeng ZY, Xu ZW, He DW, Zhao X, Ma WH, Ni WF, et al. Complications and prevention strategies of oblique lateral Interbody fusion technique. Orthop Surg. 2018;10(2):98-106.

13. Kwon YK, Jang $J H$, Lee $C D$, Lee $S H$. Fracture of the $L-4$ vertebral body after use of a stand-alone interbody fusion device in degenerative spondylolisthesis for anterior L3-4 fixation. J Neurosurg Spine. 2014;20(6): 653-6.

14. Mehren C, Mayer HM, Zandanell C, Siepe CJ, Korge A. The oblique anterolateral approach to the lumbar spine provides access to the lumbar spine with few early complications. Clin Orthop Relat Res. 2016;474(9):2020-7.

15. Meyerding HW. Spondylolisthesis. Sur Gynecol Obstet. 1932:54:371-7.

16. Davis TT, Hynes RA, Fung DA, Spann SW, MacMillan M, Kwon B, et al. Retroperitoneal oblique corridor to the L2-S1 intervertebral discs in the lateral position: an anatomic study. J Neurosurg Spine. 2014;21(5):785-93.

17. Yoo JS, Min SH, Yoon SH, Hwang CH. Paraspinal muscle changes of unilateral multilevel minimally invasive transforaminal interbody fusion. J Orthop Surg Res. 2014;9:130.

18. Tsutsumimoto $\mathrm{T}$, Shimogata $\mathrm{M}, \mathrm{Ohta} \mathrm{H}$, Misawa $\mathrm{H}$. Mini-open versus conventional open posterior lumbar interbody fusion for the treatment of lumbar degenerative spondylolisthesis: comparison of paraspinal muscle damage and slip reduction. Spine (Phila Pa 1976). 2009;34(18):1923-8.

19. Suwa H, Hanakita J, Ohshita N, Gotoh K, Matsuoka N, Morizane A Postoperative changes in paraspinal muscle thickness after various lumbar back surgery procedures. Neurol Med Chir (Tokyo). 2000;40(3):151-4 discussion 4-5.

20. Fritzell P, Hagg O, Wessberg P, Nordwall A, Swedish Lumbar Spine Study G. Chronic low back pain and fusion: a comparison of three surgical techniques: a prospective multicenter randomized study from the Swedish lumbar spine study group. Spine (Phila Pa 1976). 2002;27(11):1131-41.

21. Barker KL, Shamley DR, Jackson D. Changes in the cross-sectional area of multifidus and psoas in patients with unilateral back pain: the relationship to pain and disability. Spine (Phila Pa 1976). 2004;29(22):E515-9.
22. Hultman G, Nordin M, Saraste H, Ohlsen H. Body composition, endurance, strength, cross-sectional area, and density of MM erector spinae in men with and without low back pain. J Spinal Disord. 1993;6(2):114-23.

23. Hu ZJ, He J, Zhao FD, Fang XQ, Zhou LN, Fan SW. An assessment of the intra- and inter-reliability of the lumbar paraspinal muscle parameters using CT scan and magnetic resonance imaging. Spine (Phila Pa 1976). 2011; 36(13):E868-74

24. Bresnahan LE, Smith JS, Ogden AT, Quinn S, Cybulski GR, Simonian N, et al. Assessment of Paraspinal muscle cross-sectional area after lumbar decompression: minimally invasive versus open approaches. Clin Spine Surg. 2017;30(3):E162-E8.

25. Ghiasi MS, Arjmand N, Shirazi-Adl A, Farahmand F, Hashemi H, Bagheri S, et al. Cross-sectional area of human trunk paraspinal muscles before and after posterior lumbar surgery using magnetic resonance imaging. Eur Spine J. 2016:25(3):774-82.

26. Strube P, Putzier M, Streitparth F, Hoff EK, Hartwig T. Postoperative posterior lumbar muscle changes and their relationship to segmental motion preservation or restriction: a randomized prospective study. J Neurosurg Spine. 2016:24(1):25-31.

27. Kawaguchi $Y$, Matsui $H$, Tsuji $H$. Back muscle injury after posterior lumbar spine surgery. Part 2: Histologic and histochemical analyses in humans. Spine (Phila Pa 1976). 1994;19(22):2598-602.

28. Gejo R, Matsui $H$, Kawaguchi $Y$, Ishihara $H$, Tsuji $H$. Serial changes in trunk muscle performance after posterior lumbar surgery. Spine (Phila Pa 1976). 1999;24(10):1023-8.

29. Datta G, Gnanalingham KK, Peterson D, Mendoza N, O'Neill K, Van Dellen J, et al. Back pain and disability after lumbar laminectomy: is there a relationship to muscle retraction? Neurosurgery. 2004;54(6):1413-20 discussion 20

30. Taylor H, McGregor AH, Medhi-Zadeh S, Richards S, Kahn N, Zadeh JA, et al. The impact of self-retaining retractors on the paraspinal muscles during posterior spinal surgery. Spine (Phila Pa 1976). 2002;27(24):2758-62.

31. Hyun SJ, Kim YB, Kim YS, Park SW, Nam TK, Hong HJ, et al. Postoperative changes in paraspinal muscle volume: comparison between paramedian interfascial and midline approaches for lumbar fusion. J Korean Med Sci. 2007:22(4):646-51.

32. Kim DY, Lee SH, Chung SK, Lee HY. Comparison of multifidus muscle atrophy and trunk extension muscle strength: percutaneous versus open pedicle screw fixation. Spine (Phila Pa 1976). 2005;30(1):123-9.

33. Waschke A, Hartmann C, Walter J, Dunisch P, Wahnschaff F, Kalff R, et al. Denervation and atrophy of paraspinal muscles after open lumbar interbody fusion is associated with clinical outcome--electromyographic and CTvolumetric investigation of 30 patients. Acta Neurochir. 2014;156(2):235-44.

34. Saito T, Steinke H, Miyaki T, Nawa S, Umemoto K, Miyakawa K, et al. Analysis of the posterior ramus of the lumbar spinal nerve: the structure of the posterior ramus of the spinal nerve. Anesthesiology. 2013;118(1):88-94.

35. Steinke H, Saito T, Miyaki T, Oi Y, Itoh M, Spanel-Borowski K. Anatomy of the human thoracolumbar rami dorsales nervi spinalis. Ann Anat. 2009;191(4):408-16.

36. Regev GJ, Lee YP, Taylor WR, Garfin SR, Kim CW. Nerve injury to the posterior rami medial branch during the insertion of pedicle screws: comparison of mini-open versus percutaneous pedicle screw insertion techniques. Spine (Phila Pa 1976). 2009;34(11):1239-42.

37. Hu ZJ, Fang XQ, Zhou ZJ, Wang JY, Zhao FD, Fan SW. Effect and possible mechanism of muscle-splitting approach on multifidus muscle injury and atrophy after posterior lumbar spine surgery. J Bone Joint Surg Am. 2013; 95(24):e192 (1-9)

38. Harrop JS, Youssef JA, Maltenfort M, Vorwald P, Jabbour P, Bono CM, et al. Lumbar adjacent segment degeneration and disease after arthrodesis and total disc arthroplasty. Spine (Phila Pa 1976). 2008:33(15):1701-7.

39. Park P, Garton HJ, Gala VC, Hoff JT, McGillicuddy JE. Adjacent segment disease after lumbar or lumbosacral fusion: review of the literature. Spine (Phila Pa 1976). 2004;29(17):1938-44.

40. MCAfee PC, Farey ID, Sutterlin CE, Gurr KR, Warden KE, Cunningham BW. The effect of spinal implant rigidity on vertebral bone density. A canine model. Spine (Phila Pa 1976). 1991;16(6 Suppl):S190-7

41. Shono Y, Kaneda K, Abumi K, McAfee PC, Cunningham BW. Stability of posterior spinal instrumentation and its effects on adjacent motion segments in the lumbosacral spine. Spine (Phila Pa 1976). 1998:23(14):1550-8.

42. Strube P, Hoff E, Hartwig T, Perka CF, Gross C, Putzier M. Stand-alone anterior versus anteroposterior lumbar interbody single-level fusion after a mean follow-up of 41 months. J Spinal Disord Tech. 2012;25(7):362-9. 
43. Perez-Orribo L, Kalb S, Reyes PM, Chang SW, Crawford NR. Biomechanics of lumbar cortical screw-rod fixation versus pedicle screw-rod fixation with and without interbody support. Spine (Phila Pa 1976). 2013;38(8):635-41.

44. Pradhan BB, Nassar JA, Delamarter RB, Wang JC. Single-level lumbar spine fusion: a comparison of anterior and posterior approaches. J Spinal Disord Tech. 2002;15(5):355-61.

45. Mao L, Zhao J, Dai KR, Hua L, Sun XJ. Bilateral decompression using a unilateral pedicle construct for lumbar stenosis. Int Orthop. 2014;38(3):573-8.

\section{Publisher's Note}

Springer Nature remains neutral with regard to jurisdictional claims in published maps and institutional affiliations.

Ready to submit your research? Choose BMC and benefit from:

- fast, convenient online submission

- thorough peer review by experienced researchers in your field

- rapid publication on acceptance

- support for research data, including large and complex data types

- gold Open Access which fosters wider collaboration and increased citations

- maximum visibility for your research: over $100 \mathrm{M}$ website views per year

At $\mathrm{BMC}$, research is always in progress.

Learn more biomedcentral.com/submissions 